\title{
Effects of nitrogen input and climate trends on provincial rice yields in China between 1961 and 2003: quantitative evaluation using a crop model
}

\author{
Shinji Sawano $\cdot$ Toshihiro Hasegawa $\cdot$ \\ Yasushi Ishigooka - Tsuneo Kuwagata • \\ Junko Shindo • Fulu Tao
}

Received: 11 August 2014/Revised: 23 November 2014/Accepted: 1 December 2014/Published online: 7 December 2014

(C) The International Society of Paddy and Water Environment Engineering and Springer Japan 2014

\begin{abstract}
Analyses of the technological and climatic factors that influence regional yield can provide insights into how production systems can be improved in the future. We analyzed the effects of changes in climate and nitrogen input on the time course of rice yields of nine rice-producing provinces in China for the period between 1961 and 2003. We developed a regional-scale model that considered both climate and nitrogen flow in the rice paddy. Observed yields $\left(Y_{\mathrm{obs}}\right)$ tripled during the period, of which $65 \%$ of the increase was accounted for by the estimated yield $\left(Y_{\text {est }}\right)$ based on changes in nitrogen input and climate. The remaining $35 \%$ was attributed to other technological factors $\left(\alpha=Y_{\mathrm{obs}} / Y_{\mathrm{est}}\right)$, which include improvements in cultivars and pest management, for example. Contribution of $\alpha$ became pronounced after 1980 and accounted for 69 and $90 \%$ of the yield increases in the 1980s and 1990s, respectively. Nitrogen input had much greater impacts on $Y_{\text {est }}(90 \%)$ than did climate, but $Y_{\text {est }} /$ nitrogen input dropped substantially. Significant positive effects were observed for $\mathrm{CO}_{2}$ fertilization effects, which differed significantly among
\end{abstract}

\footnotetext{
S. Sawano · T. Hasegawa ( $) \cdot$ Y. Ishigooka · T. Kuwagata . J. Shindo

Agro-Meteorology Division, National Institute for Agro-

Environmental Sciences, 3-1-3 Kannondai, Tsukuba 305-8604, Japan

e-mail: thase@affrc.go.jp

S. Sawano

e-mail: ssawano@affrc.go.jp

Y. Ishigooka

e-mail: isigo@affrc.go.jp

T. Kuwagata

e-mail: kuwa@affrc.go.jp

J. Shindo

e-mail: jshindoh@yamanashi.ac.jp
}

provinces; their relative contribution to the increase in $Y_{\text {est }}$ ranged from 1.0 to $7.4 \%$. The effect of temperature change on $Y_{\text {est }}$ was negative and significant in three provinces, but not for the overall average. To meet future rice demand and to improve nitrogen use efficiency, full use of possible positive interactions among cultivars, nitrogen management, and climate is required.

Keywords Crop model - Global environmental change . $\mathrm{N}$ fertilizer - Oryza sativa L. P Provincial yield

\section{Introduction}

Rice (Oryza sativa L.) is the primary staple food for more than half of the world's population, produced and consumed mainly in Asia (FAO 2013). The world rice production has almost tripled since 1960, owing primarily to increases in yield per unit area rather than in production area. Demand for rice is expected to increase by about $30 \%$ from 2005/2007 to 2050 (Alexandratos and Bruinsma

Present Address:

S. Sawano

Forestry and Forest Products Research Institute (FFPRI), 1

Matsunosato, Tsukuba, Ibrakai 305-8687, Japan

Present Address:

J. Shindo

Yamanashi University, 4-4-37 Takeda, Kofu,

Yamanashi 400-8510, Japan

F. Tao

Institute of Geographical Sciences and Natural Resources

Research, Chinese Academy of Science, No.11A, Datutn Road,

Chaoyang District, Beijing 100101, China

e-mail: taofl@igsnrr.ac.cn 
2012). However, the increases in rice yield have started to slow in some Asian countries (Cassman et al. 2003; Horie et al. 2005; Peng et al. 2009). Vulnerability of the rice production system to climate change will also have significant impacts on the world food market and even a small variation in production can result in substantial fluctuation in price (IPCC 2014). Technological development to meet demand under the effects of climate change is one of the major challenges faced by food production systems.

The dramatic increase in grain yield in the second half of the twentieth century resulted from a number of factors, including improved cultural practices, breeding, agricultural chemical use, climate trends, and combinations of these factors (Evans 1993; Cassman et al. 2003). A quantitative understanding of how these factors contribute to regional yields is useful for identification of current problems and future directions for improvement of productivity. Statistical analyses have been a common approach to evaluate the trends and/or fluctuations in past yields (e.g. Lobell et al. 2011), but because multiple factors have changed concurrently, it is often difficult to untangle the effects of single factors and interactions among them.

Nitrogen $(\mathrm{N})$ fertilizer is a major driver of the increase in crop production. It increases leaf area, canopy light interception, and the rate of photosynthesis per unit leaf area, all of which lead to an increase in biomass. On the other hand, heavy use of $\mathrm{N}$ has increased the environmental load from rice agriculture (Cassman et al. 2003; Shindo et al. 2006; Shindo 2013). Future rice production must meet the growing food demand while reducing the environmental load from agriculture. In particular, this has become a major concern in China, which accounts for about $28 \%$ of world rice production and $34 \%$ of global N fertilizer consumption (as of 2011; FAOSTAT http://fao stat3.fao.org/).

Statistical analyses of recent climate trends on rice yields have detected some significant effects of climatic factors, but they often differed in magnitude and even in sign depending on the region (Tao et al. 2006, 2008; Zhang et al. 2010; Zhou et al. 2013). Climatic factors affect rice growth and yield via multiple processes and their effects are often nonlinear. The effects can also be modulated by management or cultivars, and these interactions are difficult to determine with empirical models that do not consider the mechanisms of these effects. Crop models that account for crop responses to climate and management factors are a useful tool for quantifying the factors responsible for change in production over years. Recent studies have attempted to identify the effects of climate trends or cultivar improvements on the historical yield change using crop models (Xiong et al. 2012; Yu et al. 2012; Xiao and Tao 2014). However, because efficient use of resources such as nutrients and water will become a central issue for food production, there is a need to implement model analyses to explore productivity and resource use efficiency under global climate changes.

Previously, we developed a crop model for regional rice yield in rain-fed lowland areas based on crop water use (Hasegawa et al. 2008). This model is useful for estimating crop yield with a small number of environmental variables, but does not account for two important factors that influence crop production under limited resources: $\mathrm{N}$ balance (soil $\mathrm{N}$ supply, $\mathrm{N}$ fertilizer use, and crop $\mathrm{N}$ uptake), which is essential for evaluation of environmental load from arable land, and the effect of atmospheric $\mathrm{CO}_{2}$ concentration on crop water use. On the other hand, field-scale detailed simulation models are already available for rice (e.g., Hasegawa and Horie 1997), but they require data for a number of field- and cultivar-specific parameters if they are to be applied to a regional scale.

In this study, we first modified our regional model to evaluate the effect of crop management and climatic factors on the historical changes in crop production based on our regional-scale rice yield model (Hasegawa et al. 2008) by incorporating a simple nitrogen dynamics in rice paddy field (Hasegawa and Horie 1997). We then applied this model to quantify the effects of factors associated with the time course of rice production in East Asia, using the example of China, which experienced a very rapid change in crop production and $\mathrm{N}$ use in the second half of the twentieth century. Because crop responses to climatic factors or $\mathrm{N}$ inputs are often nonlinear, we predicted that contributions of the factors would differ depending on climate zones and/or input levels.

\section{Materials and methods}

\section{Model structure}

We combined two existing models into a new simulation model driven by agrochemical and crop water use for regional-scale agricultural productivity (SACRA). SACRA is principally based on our previous regional-scale model (Hasegawa et al. 2008), but incorporates $\mathrm{N}$ dynamics from a field-scale rice model (Hasegawa and Horie 1997). SACRA also accounts for the effects of atmospheric $\mathrm{CO}_{2}$ concentration $\left(\left[\mathrm{CO}_{2}\right]\right)$ on crop water use and water use efficiency (WUE). The main features of the model are summarized below.

\section{$\mathrm{N}$ dynamics in a rice field}

The model assumes a single inorganic $\mathrm{N}$ pool $\left(N_{\text {pool }}\right)$ in the soil as a source of $\mathrm{N}$ supply to the plants. $N_{\text {pool }}$ varies during the crop growing season owing to the inflow and outflow to 
and from $N_{\text {pool }}$. In the actual paddy ecosystems, the inflow includes fertilizer $\mathrm{N}$ supply, mineralized soil and manure $\mathrm{N}$, $\mathrm{N}$ from the atmosphere (deposition) and in irrigation water, whereas the outflow includes $\mathrm{N}$ uptake by plants and $\mathrm{N}$ loss to the atmosphere, ground or surface water outside the paddy fields. In croplands, fertilizers and soil organic matter generally dominate other sources of $\mathrm{N}$ (Liu et al. 2011), although recent studies show nonnegligible contributions from the atmosphere (He et al. 2010; Katayanagi et al. 2013) and irrigation water (Kyaw et al. 2005). In this study, we used the following components to estimate daily changes in the $N_{\text {pool }}$ in the plow layer $\mathrm{d} N_{\text {pool }} / \mathrm{d} t$ :

$\mathrm{d} N_{\text {pool }} / \mathrm{d} t=N_{\mathrm{f}}+\mathrm{d} N_{\mathrm{m}} / \mathrm{d} t-\mathrm{d} N_{\text {up }} / \mathrm{d} t-\mathrm{d} N_{\text {loss }} / \mathrm{d} t$,

where $t$ is the unit of time for calculation (day), and $\mathrm{d} N_{\mathrm{m}} / \mathrm{d} t$, $\mathrm{d} N_{\text {up }} / \mathrm{d} t$, and $\mathrm{d} N_{\text {loss }} / \mathrm{d} t$ are the rates of soil $\mathrm{N}$ mineralization, crop $\mathrm{N}$ uptake, and $\mathrm{N}$ loss from rice fields, respectively. Organic $\mathrm{N}$ is a major source for crop $\mathrm{N}$ uptake and the rate of change in mineralization of soil and manure $\mathrm{N}$ is given as the first-order rate equation (Sugihara et al. 1986)

$\mathrm{d} N_{\mathrm{m}} / \mathrm{d} t=k_{\mathrm{m}} N_{\mathrm{o}} \mathrm{e}^{-k_{\mathrm{m}} t}$

$k_{\mathrm{m}}=A_{\mathrm{m}} \mathrm{e}^{-E_{\mathrm{m}} /(R(T+273))}$,

where $A_{\mathrm{m}}$ is a constant for wet soil, $E_{\mathrm{m}}$ is apparent activation energy for $\mathrm{d} N_{\mathrm{m}} / \mathrm{d} t, T$ is temperature in ${ }^{\circ} \mathrm{C}, R$ is the gas constant, and $N_{\mathrm{o}}$ is the mineralization potential, which represents the capacity of soil $\mathrm{N}$ supply during the growing season. In this study, we also account for organic fertilizer applied:

$N_{\mathrm{o}}=N_{\mathrm{o}, \text { soil }}+N_{\mathrm{o} \text {,manure }}$,

where $N_{\mathrm{o} \text {,soil }}$ is the $N_{\mathrm{o}}$ from the indigenous soil organic matter and $N_{\mathrm{o} \text {,manure }}$ is that from the applied manure. $N_{\mathrm{o} \text {,soil }}$ may vary with soil type, but in this study we fixed this value as $70 \mathrm{~kg} \mathrm{ha}^{-1}$, which is commonly observed in the paddy field in temperate regions (Toriyama 2002). $N_{\text {o,manure }}$ is expressed as a function of applied organic manure, which we derived from various incubation studies by Sugihara et al. (1986):

$$
\begin{aligned}
N_{\mathrm{O}, \text { manure }}= & -3.34 \times 10^{-8} \mathrm{~N}_{\mathrm{ma}}^{3}+1.68 \times 10^{-5} N_{\mathrm{ma}}^{2}-2.07 \\
& \times N_{\mathrm{ma}}+0.172,
\end{aligned}
$$

where $N_{\text {ma }}$ is manure $\mathrm{N}$ fertilizer input $\left(\mathrm{g} \mathrm{m}^{-2}\right)$.

Crop $\mathrm{N}$ uptake is limited by crop demand for $\mathrm{N}$ or soil $\mathrm{N}$ supply (Seligman et al. 1975). The crop demand for $\mathrm{N}$ $\left(N_{\mathrm{dem}}\right)$ is driven by the daily biomass gain and maximum crop $\mathrm{N}$ concentration $\left(\mathrm{NC}_{\max }, \mathrm{g} \mathrm{g}^{-1}\right)$.

$\mathrm{d} N_{\mathrm{dem}} / \mathrm{d} t=N C_{\max } \times \mathrm{d} W / \mathrm{d} t$
$\mathrm{NC}_{\text {max }}$ decreases as the crop biomass increases (Greenwood et al. 1991) and is expressed as:

$N C_{\max }=0.0040 \mathrm{e}^{-c_{1} B}$,

where $B$ is the total biomass $\left(\mathrm{g} \mathrm{m}^{-2}\right)$, and $c_{1}$ is an empirical constant. The rate of crop $\mathrm{N}$ uptake $\left(\mathrm{d} N_{\mathrm{up}} / \mathrm{d} t\right)$ is limited by the smaller of $N_{\mathrm{dem}}$ or $\mathrm{N}$ available in the $\mathrm{N}$ pool $\left(N_{\mathrm{avl}}\right)$ :

$\mathrm{d} N_{\mathrm{up}} / \mathrm{d} t=\min \left(d N_{\mathrm{dem}} / \mathrm{d} t, \mathrm{~d} N_{\mathrm{avl}} / \mathrm{d} t\right)$

$N_{\text {avl }}=N_{\text {pool }} \times f(B)$,

where $f(B)$ is the empirical function for relative degree of root system development, with the maximum being 1 :

$f(B)=\min \left(c_{2} \times \mathrm{e}^{c_{3} B}, 1\right)$

where $c_{2}$ and $c_{3}$ are constants. The loss of $\mathrm{N}$ from rice fields can occur through several pathways such as denitrification, volatilization, runoff, and leaching, but we assumed that $N_{\text {loss }}$ is proportional to the $N_{\text {pool }}$. We set the relative loss rate at 0.03 day $^{-1}$ as used in Hasegawa and Horie (1997).

Crop growth

Leaf area development and fraction of light intercepted by canopy

Leaf area index (LAI) increase is highly dependent on $\mathrm{N}$ availability in the soil. The allometric relation between leaf area and crop $\mathrm{N}$ has been used in some crop models (Hasegawa and Horie 1997; Yin et al. 2003; Lemaire et al. 2007). When $\mathrm{N}$ supply is limited, old leaves translocate their $\mathrm{N}$ to developing leaves (Yoneyama and Sano 1978; Gastal and Lemaire 2002), so that leaf area continues to grow at the expense of decreased $\mathrm{N}$ concentration in the crop organs (i.e., dilution). Translocation can occur without the death of lower leaves as long as $\mathrm{N}$ concentration exceeds the lowest limit of plant $\mathrm{N}$ concentration. Expansion of leaf area at a given $\mathrm{N}$ availability is also dependent on temperature (Hasegawa et al. 1999). Daily LAI increase was principally expressed as a function of daily $\mathrm{N}$ uptake and daily temperature as follows:

$$
\begin{aligned}
\mathrm{dLAI} / \mathrm{d} t= & \mathrm{LPN} \times \mathrm{d} N_{\mathrm{up}} / \mathrm{d} t \times\left(1-(\mathrm{DVI} / 1.8)^{c_{4}}\right. \\
& \times\left(1+\mathrm{e}^{-c_{5} \times\left(T-c_{6}\right)}\right)^{-1}, \quad \text { when } \mathrm{d} N_{\text {up }}<N \mathrm{a}_{\mathrm{vl}},
\end{aligned}
$$

where LPN is the maximum LAI production per unit $\mathrm{N}$ uptake, $T$ is temperature, $c_{4}$ to $c_{6}$ are empirical coefficients, and DVI is the value of the developmental index from the crop phenology model. The amount of $\mathrm{N}$ that can be transferred for leaf development is described as

$N_{\text {trans }}=T N_{\text {up }}-N C_{\text {min }} \times B$ 


$$
\begin{aligned}
\mathrm{dLAI} / \mathrm{d} t= & \mathrm{LPN} \times\left(\frac{\mathrm{d} N_{\mathrm{up}}}{\mathrm{d} t}+N_{\text {trans }} / c_{7}\right) \\
& \times\left(1-(\mathrm{DVI} / 1.8)^{c_{4}} \times\left(1+\mathrm{e}^{-c_{5} \times\left(T-c_{6}\right)}\right)^{-1},\right. \\
& \text { when } d N_{\mathrm{up}} \geq N_{\mathrm{avl}},
\end{aligned}
$$

where $N_{\text {trans }}$ is the translocated $\mathrm{N}, T N_{\text {up }}$ is the total amount of crop $\mathrm{N}$ uptake for leaf development, and $c_{7}$ is a time constant for translocated $\mathrm{N}$. The enhanced canopy cover accelerates daily biomass gain by increasing the light interception. The fraction of light interception (FLI) by the canopy is obtained using Beer's Law:

FLI $=1-\mathrm{e}^{-k \times \mathrm{LAI}}$,

where $k$ is the extinction coefficient of the canopy, which we set to a constant value of 0.55 .

\section{Crop water use, biomass accumulation, and grain yield}

Crop carbon assimilation results from canopy $\mathrm{CO}_{2}$ exchange and the conversion of photosynthate into biomass. These processes are mainly driven by three environmental factors: solar radiation, $\mathrm{CO}_{2}$ supply, and water, and most existing crop models incorporate these factors. In this study, we used a water-driven approach to model rice growth as in Hasegawa et al. (2008) and Steduto et al. (2009), because this approach approximates well the resource-limited growth and yield (Steduto et al. 2009).

Biomass $(B)$ increases in proportion to crop water use so that WUE is relatively unaffected by other environmental factors (Gregory 2004). However, vapor pressure deficit (VPD) has a strong effect on WUE and should be considered when the model is applied to a range of climatic zones. To account for the effect of VPD, we first converted VPD (hPa) to vapor concentration deficit (VCD; $\mathrm{kg} \mathrm{m}^{-3}$ ) using the equation of the state of an ideal gas and then calculated the adjusted WUE (WUE $\mathrm{V}_{\mathrm{v}} \mathrm{g} \mathrm{kg}^{-1}$ ) using VCD (Sinclair et al. 1984):

$\mathrm{VCD}=\frac{n \mathrm{VPD}}{R(T+273)}$

$\mathrm{WUE}_{\mathrm{v}}=K_{\mathrm{t}} / \mathrm{VCD}$,

where $n$ is the molecular weight of water, $R$ is the gas constant, $T$ is the temperature in degrees Celsius, $K_{\mathrm{t}}$ is the proportionality factor of crop water use to biomass (uncorrected WUE). We set $K_{\mathrm{t}}$ at $30.8 \times 10^{-3} \mathrm{~g} \mathrm{~m}^{-3}$ based on the observation of rice plants by Adachi (1997). Atmospheric $\mathrm{CO}_{2}$ concentration $\left(\left[\mathrm{CO}_{2}\right]\right)$ has a significant effect on WUE through enhancement of $\mathrm{CO}_{2}$ assimilation. This effect needs to be incorporated in a long-term yield analysis as $\left[\mathrm{CO}_{2}\right]$ has increased by as much as $25 \%$ in the period between 1960 and 2009 (http://www.esrl.noaa.gov/ $\mathrm{gmd} / \mathrm{ccgg} /$ trends/). WUE can sometimes be approximated by a linear function of $\left[\mathrm{CO}_{2}\right]$, but this could potentially overestimate the effect of $\left[\mathrm{CO}_{2}\right]$ because under high $\left[\mathrm{CO}_{2}\right]$ assimilation is not limited by $\mathrm{CO}_{2}$ supply (Farquhar et al. 1980). We therefore used a Michaelis-Menten-type rectangular hyperbola function for the $\left[\mathrm{CO}_{2}\right]$-dependent WUE $\left(\mathrm{WUE}_{\mathrm{cv}}\right)$ :

$\mathrm{WUE}_{\mathrm{cv}}=\mathrm{WUE}_{\mathrm{v}} \times c_{8}\left[\mathrm{CO}_{2}\right] /\left(\mathrm{K}_{\mathrm{c}}+\left[\mathrm{CO}_{2}\right]\right)$

where $K_{\mathrm{c}}$ is the Michaelis-Menten coefficient, and $c_{8}$ is an empirical parameter. We estimated $c_{8}$ and $K_{\mathrm{c}}$ based on a freeair $\mathrm{CO}_{2}$ enrichment experiment, in which WUE increased by $19 \%$ with an increase in $\mathrm{CO}_{2}$ concentration of $200 \mu \mathrm{mol} \mathrm{mol}^{-1}$ (Yoshimoto et al. 2005) $\left(c_{8}=1.882\right.$; $K_{\mathrm{c}}=341.283$ ). Crop water use depends on three factors: physical evaporative demand, canopy establishment, and stomatal conductance. The physical evaporative demand can be approximated by the Food and Agriculture Organization of the United Nations (FAO) reference evapotranspiration $\left(\mathrm{mm} \mathrm{day}^{-1}\right)$ modified by Ishigooka et al. (2008) $\left(\mathrm{ET}_{0}\right)$. We used FLI to represent the degree of canopy cover. $\left[\mathrm{CO}_{2}\right]$ also affects transpiration of the canopy via decreased stomatal conductance. Taken collectively, crop water use (CWU; mm day $^{-1}$ ) can be approximated as:

$\mathrm{CWU}=\mathrm{ET}_{\mathrm{o}} \times\left(c_{9}\left[\mathrm{CO}_{2}\right]+c_{10}\right) \times \mathrm{FLI}$,

where $c_{9}$ and $c_{10}$ are empirical coefficients. Parameters $c_{9}$ and $c_{10}$ were also estimated based on the FACE experiment (Yoshimoto et al. 2005), where transpiration decreased by $8.2 \%$ in response to $\left[\mathrm{CO}_{2}\right]$ elevated by $200 \mu \mathrm{mol} \mathrm{mol}^{-1}$ $\left(c_{9}=-0.00041, c_{10}=1.15867\right)$.

Finally, biomass growth and grain yield $(Y)$ are determined as:

$\mathrm{d} B / \mathrm{d} t=\mathrm{WUE}_{\mathrm{cv}} \times \mathrm{CWU}$

$Y=\mathrm{HI} \times B$,

where $\mathrm{HI}$ is the harvest index, set at 0.488 as a representative value for modern high-yielding varieties planted in Asian countries, based on the mean $\mathrm{HI}$ observed in a variety trial (Cui et al. 2000). HI has been substantially improved through breeding over the period studied (Evans 1993), but we have rather used the fixed HI to evaluate technological improvement including breeding as detailed in the subsequent section for analysis of factors that affected historical yield change.

\section{Study area}

We selected nine major rice-growing provinces in China (Table 1), which produced about $80 \%$ of the total rice production in 2004. The nine provinces ranged from about 20 to $50^{\circ} \mathrm{N}$ and thus covered the range of climates in the major rice-growing regions of East Asia. 


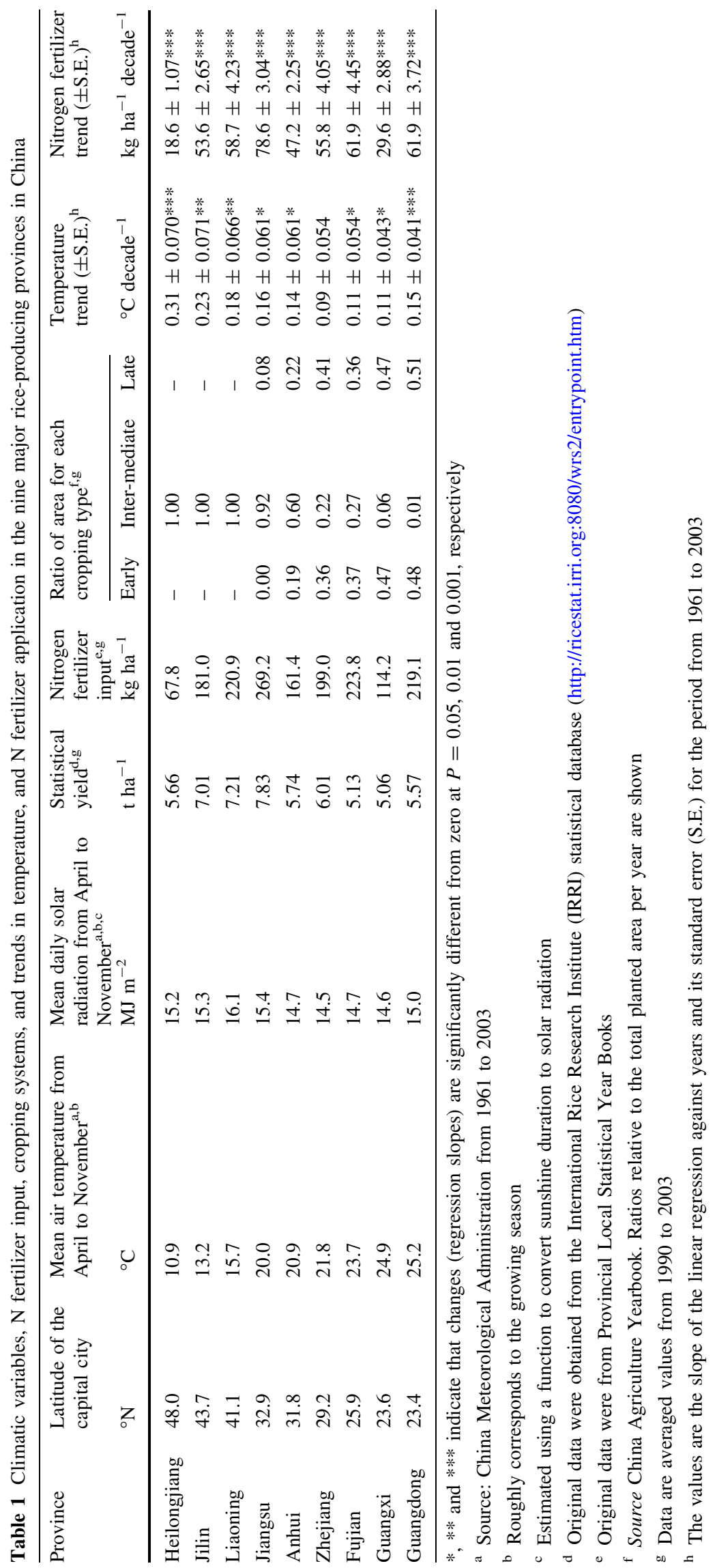


Data

\section{Climate data}

Climate data were obtained from China Meteorological Administration, China (http://cdc.cma.gov.cn/home.do). The database includes daily climate data from approximately 200 stations across the country. We used data from all weather stations (3-4 stations in each province) in the nine provinces. The meteorological dataset included average temperature, sunshine duration, precipitation, vapor pressure, and wind speed from 1961 to 2003. Solar radiation data were not available, so we estimated it by converting sunshine duration to daily solar radiation using the equation proposed by Xu et al. (2011). For $\left[\mathrm{CO}_{2}\right]$, we used annual mean $\left[\mathrm{CO}_{2}\right]$ data measured at Mauna Loa from the National Oceanic and Atmospheric Administration (NOAA, http://www.esrl.noaa.gov/gmd/ccgg/trends/ co2_annmean_mlo.txt).

\section{Nitrogen input}

We used data for both inorganic and organic $\mathrm{N}$ fertilizer sources. The amounts of inorganic $\mathrm{N}$ applied were obtained from Provincial Local Statistical Year Books (National Bureau of Statistics of China, 1981-2004). These series of statistics cover provincial-level $\mathrm{N}$ consumption in agriculture from 1980 to 2003. Inorganic $\mathrm{N}$ application before 1980, however, was available only at the national level (FAOSTAT, http://faostat3.fao.org/). The $\mathrm{N}$ input data between 1961 and 1979 at the provincial level were estimated from the national-scale $\mathrm{N}$ data by weighting fertilizer use in each province relative to the national total use in 1980, assuming that the values were unchanged between 1961 and 1980. Note that the changes in the rank and relative fertilizer used among provinces were little changed between 1980 and 2003. The decadal change in the manure $\mathrm{N}$ consumption data in major production areas was obtained from Zou et al. (2009).

\section{Phenology and crop calendar}

Crop phenology, timing and progress of crop development as affected by climatic variables is an essential component of a crop growth model and is highly sensitive to changes in temperature and cultivars used (Ritchie and NeSmith 1991; Horie 1994). Various types of crop phenology models have been developed and used in rice growth models (reviewed by Zhang and Tao 2013), but those used for a wide range of environmental conditions generally include functions of temperature and day length to account for photoperiod and temperature sensitivities (Nakagawa and Horie 1995; Yin et al. 1997; Sawano et al. 2008). In these models, parameters are specific to each cultivar estimated from controlled-environment or field experiments. Unfortunately, information is limited on rice cultivars specifically planted in the target regions during the period of interest. Therefore, we used phenology models and/or parameters reported for both japonica -type and indica-type cultivars planted in four different latitudinal zones, in a similar manner to that of Zhang and Tao (2013), though the latter authors defined three zones across China. For short-duration japonica-type cultivars planted in a northeastern province (Heilongjiang), we used a crop clock model by Shimono et al. (2007) for Kirara 397. In Jilin and Liaoning, a short to intermediate-duration japonica cultivar, Akitakomachi, was assumed with a similar model to that of Shimono et al. (2007) with the parameters estimated from the data of Kim et al. (2003). These two cultivars are adapted to relatively high latitudes and therefore are nonphotoperiod-sensitive. In three provinces in central China along the Yangtze River (Jiangsu, Anhui, and Zhejiang), a late japonica-type cultivar, Hinohikari, was assumed and in three southern provinces (Fujian, Guangxi, and Guangdong), IR36, an indica cultivar adapted to tropical climates was used. For these photoperiod-sensitive cultivars, a phenology model proposed by Horie et al. (1995) and Nakagawa and Horie (1995) was used. The parameters for Hinohikari in the Nakagawa and Horie (1995) model were obtained from Hasegawa et al. (1995).

Planting time is another important element in the crop calendar and could be a primary adaptation measure under climate change. Earlier or later planting than at present can make a significant difference in growth duration in response to climate change (Zhang and Tao 2013). Planting time also varies from field-to-field within each region. Frequency distribution of transplanting time within a target area is an effective means to improve model performance for regional-scale yield estimation (Stehfest et al. 2007; Sawano et al. 2008). Previously, we expressed a frequency distribution of planting time as a function of precipitation for the rain-fed lowland production system (Sawano et al. 2008), but in the present study, because irrigated lowland is the most common system, we assumed a fixed normal distribution in each province with the initial and terminal dates given in Yan et al. (2003).

\section{Provincial yield data}

Rice production data in each province were obtained from the International Rice Research Institute (IRRI) statistical database (http://ricestat.irri.org:8080/wrs2/entrypoint.htm). The database provides planted area, production, and yield data in each province from 1951 to 2004. Where double cropping is available, planted areas for the first and second crops were obtained from the China Agriculture Yearbook (China Agriculture Press 1981-2004). In southern 
provinces such as Fujian, Guanxi and Guandong, triple cropping is also practiced in the paddy ecosystem. In most of the triple cropping, however, two rice crops are combined with another crop such as vegetables (Frolking et al. 2002), and triple rice cropping is not explicitly shown in the year book.

\section{Calculation of provincial yield}

We calculated provincial yield in the following steps. First, the model calculated growth and grain yield for a crop planted on a given date with daily climate data and seasonal $\mathrm{N}$ input. This was repeated from the onset and final dates of transplanting at weather stations in each province. They were then weighted by the ratio of area transplanted on each date. Where double cropping is practiced, we repeated these steps for both early and late crops. Finally, annual regional yield was estimated by weighting the average by the ratio of land area between cropping seasons. To test whether the model accounts for the spatial variation in grain yield, we ran SACRA for the period between 1990 and 2003 in nine major rice-producing provinces (Table 1).

\section{Analysis of factors that affected historical yield change}

The model developed here accounts for the effects of changes in the amount of $\mathrm{N}$ fertilizer and climatic factors such as temperature and $\left[\mathrm{CO}_{2}\right]$, which have changed over the past decades (Table 1). In addition, technological factors other than $\mathrm{N}$ input could make significant contributions to regional yield increase for the same period, but the current model is not capable of simulating the effects of these technological factors. We therefore analyzed these factors associated with the regional yield via two steps. First, we estimated the regional yields $\left(Y_{\text {est }}\right)$ of each province using the real climate and $\mathrm{N}$ input data during the period from 1961 to 2003. Because we did not change any parameters in the model over the years, $Y_{\text {est }}$ can be considered as a yield attainable under the climatic and $\mathrm{N}$ input conditions with fixed technological factors. By comparing $Y_{\text {est }}$ and regional statistical yield $\left(Y_{\text {obs }}\right)$, we can quantify the changes in the other technological factors as

$\alpha=Y_{\text {obs }} / Y_{\text {est }}$,

where $\alpha$ represents yield improvement corrected by changes in $\mathrm{N}$ input and climate changes.

Second, we ran the SACRA model with a combination of hypothetical forcing variables for the same period by changing $\left[\mathrm{CO}_{2}\right]$ and temperature:

Case 1 actual changes in $\mathrm{N}$, temperature, and $\left[\mathrm{CO}_{2}\right]$

Case 2 actual change in $\mathrm{N}$ and no change in temperature or $\left[\mathrm{CO}_{2}\right]$
Case 3 actual change in $\left[\mathrm{CO}_{2}\right]$ and no change in $\mathrm{N}$ or temperature

Case 4 actual change in temperature and no change in $\mathrm{N}$ and $\left[\mathrm{CO}_{2}\right]$

Control no change in $\mathrm{N}$ input, temperature, or $\left[\mathrm{CO}_{2}\right]$ from 1961

For cases with no change in $\left[\mathrm{CO}_{2}\right]$ or $\mathrm{N}$, we fixed the values of $\mathrm{N}$ or $\left[\mathrm{CO}_{2}\right]$ in 1961. Actual changes were used for $\mathrm{N}$ or $\left[\mathrm{CO}_{2}\right]$ under Cases 1-3. For the temperature data, we first calculated nine-year moving averages of the mean temperature from April to November, which roughly cover the growing seasons across different provinces, to determine the temperature trend for the whole period. In cases with no change in temperature (Cases 2, 3, and Control), differences between the moving average and AprilNovember mean temperature of the year of interest were added to the daily temperature data in 1961 . The effects of $\mathrm{N},\left[\mathrm{CO}_{2}\right]$, and temperature on changes in yield can be quantified by subtracting $Y_{\text {est }}$ under Control from that under Cases 1,3 , or 4 , respectively.

\section{Results and discussion}

Spatial variability of climate and management

The nine provinces studied differed largely in climatic conditions, cropping systems, levels of $\mathrm{N}$ input, and grain yield (Table 1). Average temperatures from April to November ranged from $10.9{ }^{\circ} \mathrm{C}$ in Heilongjiang to $25.2{ }^{\circ} \mathrm{C}$ in Guangdong. Increases in temperature during the period between 1961 and 2003 were significant in all provinces, except in Zhejiang, and the decadal rates of change ranged from 0.09 to $0.31{ }^{\circ} \mathrm{C}$. Three provinces located in the northeastern part of the country, where current temperatures are low, showed higher rates of temperature increase. Daily solar radiation averaged for the same period was between $14.5 \mathrm{MJ} \mathrm{m}^{-2}$ in Zhejiang and $16.1 \mathrm{MJ} \mathrm{m}^{-2}$ in Liaoning. The proportion of double cropping increased as the average temperature increased above $20^{\circ} \mathrm{C}$ (Table 1). Nitrogen fertilizer inputs, averaged for the period 1990-2003, differed by as much as fourfold among the provinces, ranging from $68 \mathrm{~kg} \mathrm{ha}^{-1}$ in Heilongjiang to $269 \mathrm{~kg} \mathrm{ha}^{-1}$ in Jiangsu. Increases in $\mathrm{N}$ fertilizer use between 1961 and 2003 also differed significantly among the provinces, indicating that the gap in $\mathrm{N}$ inputs among provinces widened during the period studied. It should be noted, however, that the national $\mathrm{N}$ fertilizer input levels increased dramatically for the 16-year period from 1961 to 1976, but the increase slowed in the mid-1980s, and plateaued in the mid-1990s (Fig. 1). Grain yield averaged 


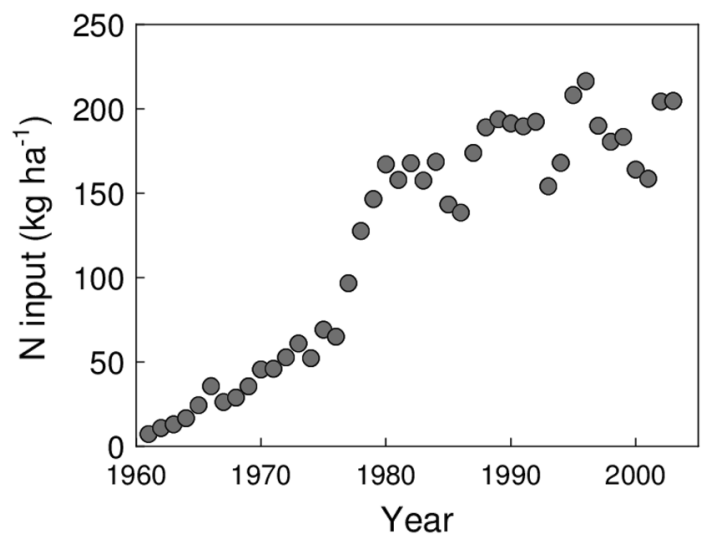

Fig. 1 Changes in $\mathrm{N}$ fertilizer input averaged over nine provinces

for the period 1990-2003 also ranged widely from 5.06 to $7.83 \mathrm{t} \mathrm{ha}^{-1}$.

Spatial variation in provincial yield and partial factor productivity for $\mathrm{N}$

Estimated grain yields for the period from 1990 to 2003 were slightly smaller than observed grain yields by $0.56 \mathrm{t} \mathrm{ha}^{-1}$ when averaged across the nine provinces (Fig. 2a), but spatial variation and ranking of provincial yields were similar between observed and estimated yields, with an root mean square error (RMSE) value of $0.82 \mathrm{t} \mathrm{ha}^{-1}$, equivalent to $14 \%$ of the observed average.

Partial factor productivity (PFP) for $\mathrm{N}$, defined as the grain yield per unit $\mathrm{N}$ applied, also varied substantially from 23 to $83 \mathrm{~kg} \mathrm{~kg}^{-1}$. Estimated PFP agreed well with the observed value with an RMSE of $5.9 \mathrm{~kg} \mathrm{~kg}^{-1}$, equivalent to $15 \%$ of the observed average (Fig. 2b). Because PFP for
$\mathrm{N}$ is considered to be a representative measure of $\mathrm{N}$ fertilizer use efficiency (Peng et al. 1995), the model provides a good reflection of the spatial variation in $\mathrm{N}$ fertilizer use efficiency.

Estimated and observed changes in regional yields

Observed grain yields averaged over nine provinces have almost tripled since1961 (Fig. 3a). The rate of increase was pronounced until the 1980 s, exceeding $5 \%$ per year relative to the yield in 1961, but slowed in the 1990s. The value of $\alpha$, representing yield improvement corrected by changes in $\mathrm{N}$ input and climate changes, remained unchanged until the late 1970s, but subsequently $\alpha$ increased sharply and the rate of increase was almost comparable to that in the observed yield. This result suggests that the estimated yield showed a similar trend to the observed yield during the period from 1960 to 1980 but that the subsequent increase was not accounted for by the model. For the entire 43-year study period, $\alpha$ averaged over nine provinces increased by as much as $71 \%$, which was about $35 \%$ of the yield increase (Fig. 3a). Much of the increase occurred after 1980; the rate of increase in $\alpha$ amounted to $69 \%$ of that in the observed yield in the $1980 \mathrm{~s}$ and $90 \%$ of that in the 1990s. Therefore, other technological factors lumped in $\alpha$ were indicated to be the major driver of yield enhancement during the 1980s and 1990s.

One of the major technological advancements for the period studied was cultivar improvement, and particularly development of hybrid rice cultivars, which show an approximately $10-20 \%$ yield advantage over conventional inbred cultivars (Cheng et al. 2004). Areas planted to hybrid rice rose sharply from the late 1970s: $0.4 \%$ in 1976,
Fig. 2 Comparison between estimated and measured rice yield (a) and partial factor productivity (PFP) for $\mathrm{N}$ (yield/ $\mathrm{N}$ input) (b) in nine provinces in China averaged over the 1990-2003 period. RMSE root mean square error, $M D$ mean difference between observed and estimated yields (or bias)

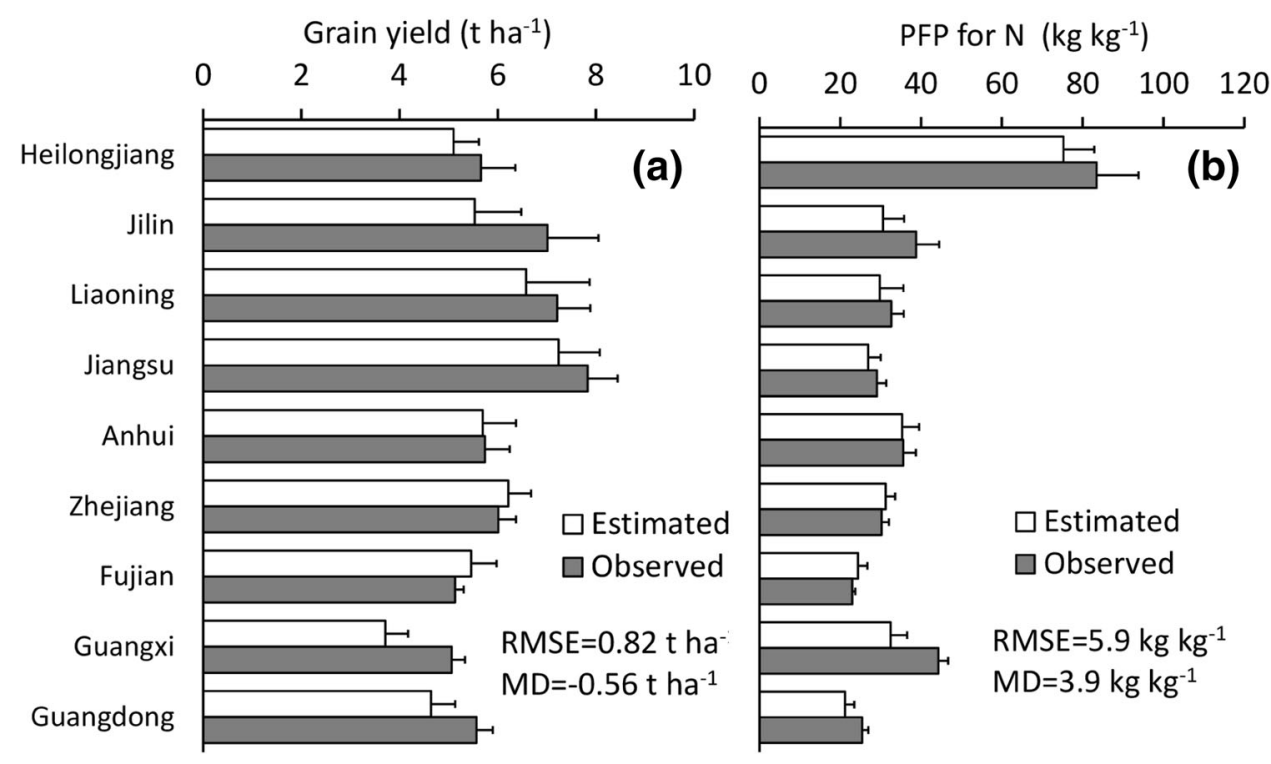




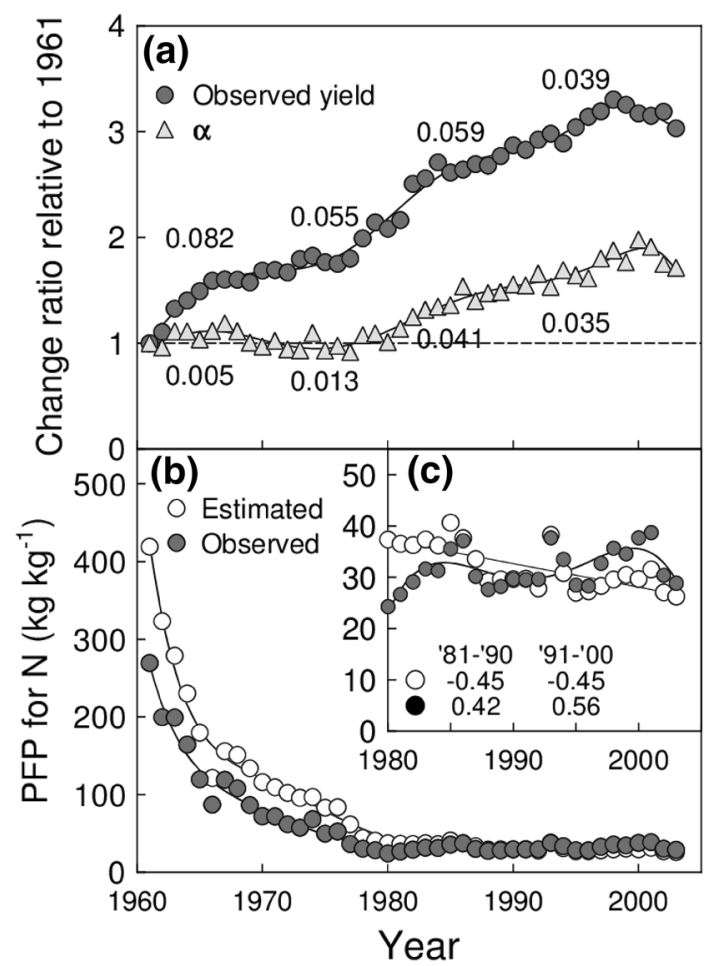

Fig. 3 Changes in observed yield and $\alpha$ (observed/estimated yield) relative to the values in 1961 (a) and in partial factor productivity (PFP) for $\mathrm{N}$ (yield/N input) (b) and (c) for the data averaged over nine provinces. Values specified in (a) and (c) are slopes (derivatives) of the polynomial fitted to the data at the mid-time point of each decade

$17 \%$ in 1982, $4 \%$ in 1990, and $55 \%$ in 2002 (Cheng et al. 2004). This corresponds to the period in which $\alpha$ increased substantially. In major $\mathrm{C}_{3}$ cereals, genetic improvement in grain yield during the green revolution was realized through a large increase in HI (Evans 1993). For inbred indica cultivars, historical change in HI was summarized using the cultivars released by IRRI from 0.32 to 0.46 (Evans 1993) and from 0.28 to 0.55 in Peng et al. (2000). According to Song et al. (1990), the change in HI in the dominant cultivars planted in Zhejiang province was from 0.38 in native cultivars to 0.51 in new improved cultivars. The importance of genetic improvement since 1980 was also reported by $\mathrm{Yu}$ et al. (2012), who used the Agro-C model to analyze regional yields and associated factors.

On the other hand, PFP for $\mathrm{N}$ decreased substantially over the past 43 years (Fig. 3b). This was largely associated with the sharp increase in $\mathrm{N}$ input, particularly in the period between 1960 and 1980. The estimated PFP for $\mathrm{N}$ showed a similar change to the observed value, though the model overestimated PFP for $\mathrm{N}$ for the first 20 years (Fig. 3b). From 1980 onwards, PFP for $\mathrm{N}$ was relatively unchanged at about $30 \mathrm{~kg} \mathrm{~kg}^{-1}$, lower than that reported for maize in the United States $\left(57 \mathrm{~kg} \mathrm{~kg}^{-1}\right.$, Cassman et al. 2002). However, while the estimated PFP continued to decrease from 1980, the observed PFP increased consistently over the same period, overtaking the estimated value in the early 1990s. A slight but consistent increase in PFP indicated that some improvement in the fertilizer use efficiency has also contributed to the rise in $\alpha$ and regional yield, although overuse of $\mathrm{N}$ is still one of the key problems in rice production in China (Peng et al. 2009).

Large yield increases occurred in all nine provinces (Fig. 4). Trends in estimated yields agreed well with the observed yields in two northeastern provinces (Heilongjiang and Jilin), but in the other provinces estimated yields rose more sharply between 1961 and 1980 and plateaued earlier than did observed yields. In central and southern China, contribution of $\alpha$ to the yield increase was relatively more important than in the northeastern provinces. This finding is consistent with the fact that adoption of hybrid rice was much higher in the southern provinces, where indica-type cultivars are commonly planted.

Contributions of $\mathrm{N}$ input, temperature, and $\mathrm{CO}_{2}$ to estimated yield changes

The combined effects of changes in $\mathrm{N}$ input, $\mathrm{CO}_{2}$, and temperature on the simulated yield gains from 1961 to the 1990s were significant in all provinces $(P<0.001)$, with an average of about $3 \mathrm{tha}^{-1}$ (Table 2). Most of the increases occurred between 1961 and 1980 and plateaued thereafter, as evidenced by the significant quadratic relation between yield gains and year (Table $2, P<0.001$ ). The yield gains differed among provinces. In general, the yield gains were larger in northeastern and central provinces than in southern provinces; Heilongjiang and Liaoning recorded twofold increases compared with Guangxi and Guangdong (Table 2).

The largest sole contributor to these gains was $\mathrm{N}$ fertilizer input, which accounted for more than $90 \%$ of the estimated yield gains averaged over nine provinces in the $1990 \mathrm{~s}$ (Table 2, comparison between $N$ vs $N, \mathrm{CO}_{2}$, and $T$ ). Nearly $90 \%$ of the increase during the whole period occurred in the first 20 years. Naturally, the yield gains with $\mathrm{N}$ input changes differed significantly among provinces, which reflected regional differences in the combined effects. Diminishing return on grain yield is apparent as $\mathrm{N}$ input exceeded the crop demand; this occurred relatively early (1960s-1980s), resulting in a drastic decrease in PFP for $\mathrm{N}$ (Fig. 3b) during this period. The regional differences in $\mathrm{N}$ effects are in part due to the level of $\mathrm{N}$ input, but the interpretation is not straightforward. The largest yield gain was observed in Heilongjiang where $\mathrm{N}$ input was smallest, followed by Jiangsu where $\mathrm{N}$ input and its increment was the largest.

Significant positive effects were observed for the effect of $\mathrm{CO}_{2}$ in all provinces (Table $2, P<0.001$ ). This was 
Fig. 4 Time course of observed yield, estimated yield, and $\alpha$ (observed/estimated yield) in nine provinces in China from 1961 to 2003. RMSE root mean square error, $M D$ mean difference between observed and estimated yields (or bias)

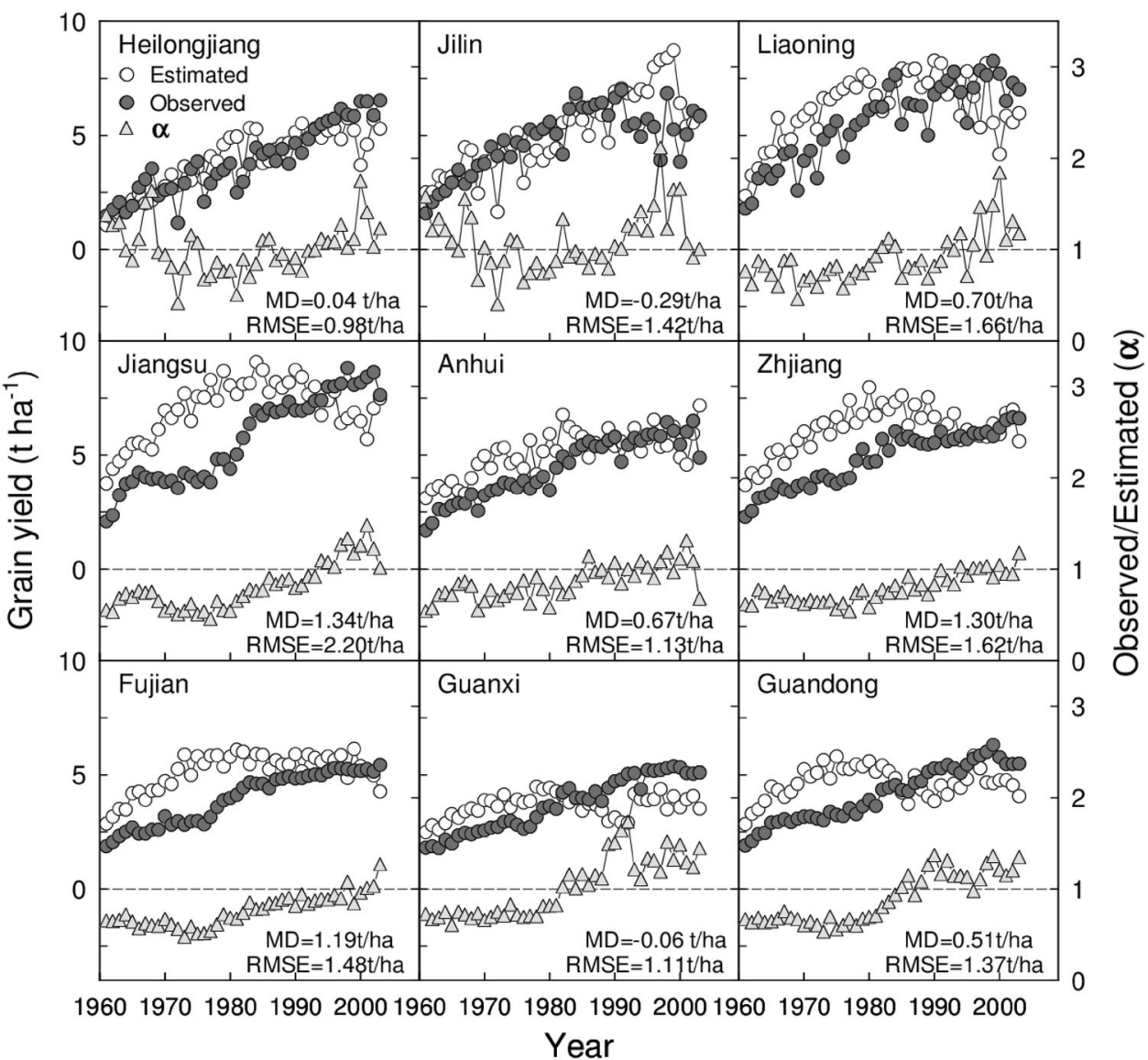

because of the linear increase in $\left[\mathrm{CO}_{2}\right]$ during the period and near-linear increase in WUE in response to elevated $\left[\mathrm{CO}_{2}\right]$ in the range between 300 and $400 \mu \mathrm{mol} \mathrm{mol}^{-1}$. The contribution of $\mathrm{CO}_{2}$ fertilization to the estimated yield in the $1990 \mathrm{~s}$ averaged $4.15 \%$ relative to that in 1961 (Table 2). Xiong et al. (2012) estimated the contribution of the $\mathrm{CO}_{2}$ fertilization effect during the period between 1961 and 2009 to be $8.7 \%$ for rice, which was larger than that estimated in the current study. It is worth noting, however, that $\left[\mathrm{CO}_{2}\right]$ has risen substantially in the last 15 years, from $317 \mu \mathrm{mol} \mathrm{mol}^{-1}$ in 1960 to $360 \mu \mathrm{mol} \mathrm{mol}{ }^{-1}$ in 1995 and $387 \mathrm{ppm}$ in 2009. This suggests that these two studies showed a comparable contribution of $\mathrm{CO}_{2}$ fertilization effect when corrected by the $\left[\mathrm{CO}_{2}\right]$ increase.

The yield gains with elevated $\left[\mathrm{CO}_{2}\right]$ differed significantly among provinces despite the assumption that changes in $\left[\mathrm{CO}_{2}\right]$ were uniform across provinces; they were smaller in the two northeastern provinces, Heilongjiang and Jilin. As a result, the relative contribution of elevated $\left[\mathrm{CO}_{2}\right]$ to regional yield was smaller in these provinces (less than $2 \%$ ) than in southern provinces, where yield gains with the combined factors were relatively small and the $\left[\mathrm{CO}_{2}\right]$ effect was relatively large (e.g., $5.5 \%$ in Guangdong and $7.4 \%$ in Guangxi). The northeastern provinces were apparently cooler and input $\mathrm{N}$ was relatively lower (Table 1) than those of the southern provinces. Ample experimental evidence indicates that $\mathrm{N}$ deficiency limits growth and yield responses to elevated $\left[\mathrm{CO}_{2}\right]$ (Makino et al. 1997; Kimball et al. 2002; Sakai et al. 2006; Yin 2013). The present model does not include a direct mechanism by which $\mathrm{N}$ deficiency limits the $\left[\mathrm{CO}_{2}\right]$ fertilization via photosynthesis or water use efficiency, but $\mathrm{N}$ conditions can affect $\left[\mathrm{CO}_{2}\right]$ response via growth enhancement by elevated $\left[\mathrm{CO}_{2}\right]$. Enhancement of biomass increases crop demand for $\mathrm{N}$, which promotes crop $\mathrm{N}$ uptake and leaf area growth, leading to a positive feedback on biomass production. Under scarce $\mathrm{N}$ conditions, crop $\mathrm{N}$ uptake is promoted by elevated $\left[\mathrm{CO}_{2}\right]$ initially but depletes $\mathrm{N}$ resources more rapidly than under ambient $\left[\mathrm{CO}_{2}\right]$. This could limit the growth responses to elevated $\left[\mathrm{CO}_{2}\right]$ where a limited amount of $\mathrm{N}$ is applied.

Low temperature is another important factor that may limit $\left[\mathrm{CO}_{2}\right]$ fertilization. One physiological explanation for this phenomenon was provided by (Long 1991), where higher temperature generally increases photorespiration of $\mathrm{C}_{3}$ plants, which reduces net photosynthesis. Elevated $\left[\mathrm{CO}_{2}\right]$ increases photosynthesis by increasing carboxylation and by decreasing photorespiration. In high 


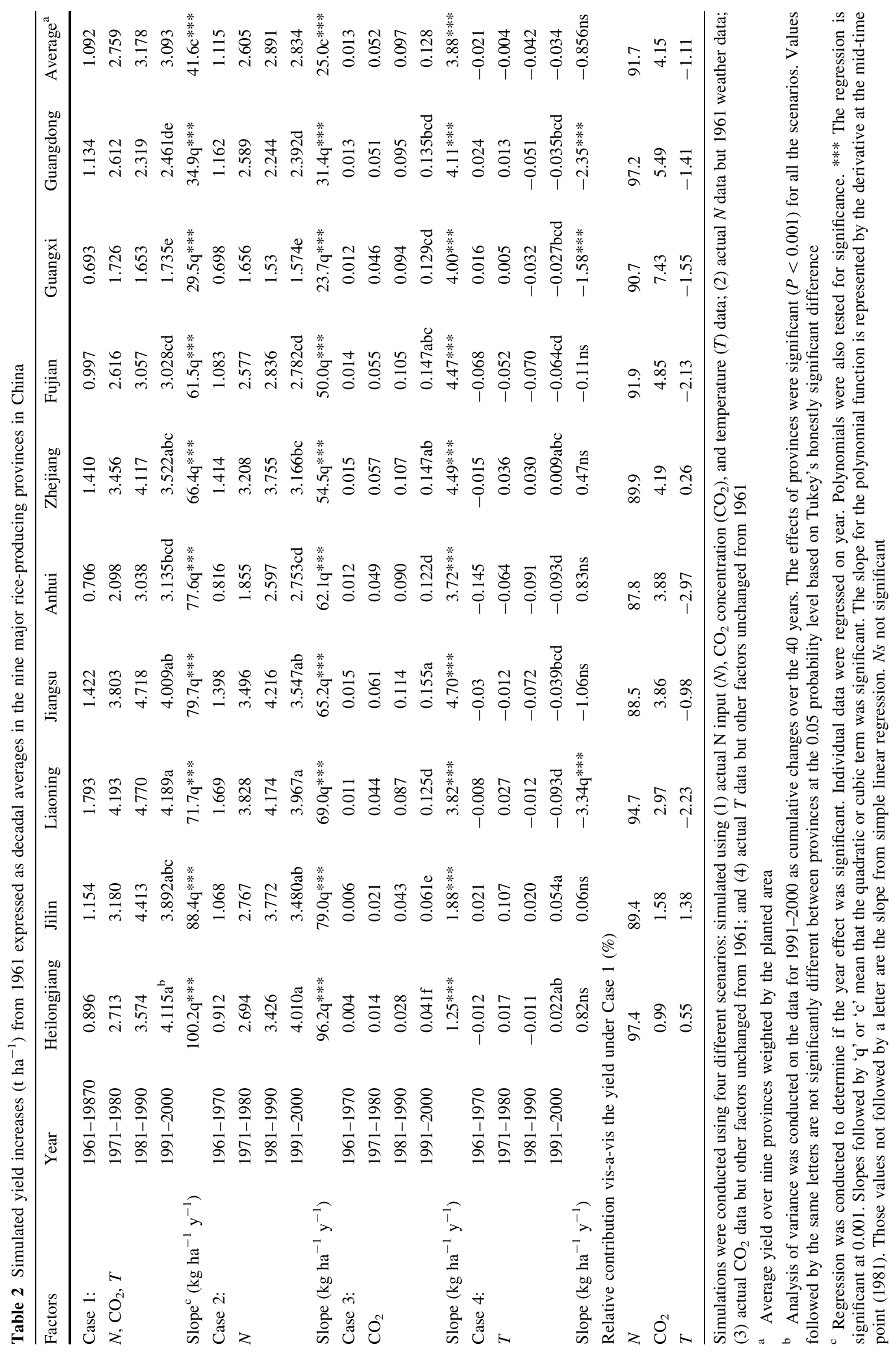


temperature ranges, the latter effect becomes more pronounced, resulting in higher photosynthetic enhancement by elevated $\left[\mathrm{CO}_{2}\right]$. However, in low temperature ranges, the effect of elevated $\left[\mathrm{CO}_{2}\right]$ on photorespiration is rather limited, resulting in a comparatively smaller photosynthetic enhancement under elevated $\left[\mathrm{CO}_{2}\right]$. This mechanism, however, is not included in the present model, but an indirect effect may be involved; low temperature affects not just crop growth but also soil processes, including $\mathrm{N}$ mineralization as shown in Eqs. (2) and (3). The crop dependence on soil mineralization is large where $\mathrm{N}$ input is low. In the model, low $\mathrm{N}$ input and low temperature interactively limited the growth enhancement by elevated $\left[\mathrm{CO}_{2}\right]$ in the northern provinces.

The sole effect of temperature change was not significant on the estimated yield averaged over the nine provinces (Table 2). This was similar to the results reported by Xiong et al. (2012). The model accounts for various effects of increases in temperature, including positive effects on nitrogen supply, leaf area growth, crop water use, and negative effects on growth duration. The positive effects were likely counterbalanced by the negative effects in the average yield, but three provinces (Liaoning, Guanxi, and Guandong) showed significant negative effects $(P<0.001)$. In these provinces, negative effects on growth duration were estimated to have surpassed the positive effects. Statistical analyses previously conducted on the historical yield data showed that, in general, increases in temperature had significant positive effects on yield in northeastern provinces (Tao et al. 2008; Zhou et al. 2013) and nonsignificant effects in the central and southern parts of China (Tao et al. 2008; Zhang et al. 2010). The positive effects of increasing temperature observed in the census yield in the northeast could be a result of reduced occurrence of chilling injuries, an extended frost-free period, and improvements in countermeasures against chilling stresses (Zhou et al. 2013). None of these factors are accounted for by the model, which could be a reason for the nonsignificant temperature effects on the estimated yields in the northeastern provinces. These empirical studies also highlighted the importance of solar radiation, which could have overridden the effects of temperature changes. The present study, which aimed to identify the sole effect using a crop model, suggested increasing temperature has an ongoing negative effect in some provinces.

Summary and implications for the future

Simulated yields by crop models generally include large uncertainties due to various sources. For example, a recent model comparison study demonstrates that crop models even at a field level show large variation in responses to temperature and elevated $\left[\mathrm{CO}_{2}\right]$ ( $\mathrm{Li}$ et al. 2014), which could be a large source of uncertainty in yield prediction under various climates. Regional yields vary spatially and temporally depending on a number of factors such as climate, soil, management practices, cultivars, and damages caused by pest and diseases, but models do not account for all the factors affecting the variations, which could be a source of gaps between observed and predicted yields. In this study, we intended to study long-term trends in provincial yields, but overlooked the year-to-year yield variability, which is often caused by environmental stresses such as extreme temperatures. We also assumed that water supply is not limited in irrigated rice fields which cover more than $90 \%$ of the paddy area in China, but water availability is becoming a concern for the future rice production (GRiSP 2013). High-quality and high-resolution model input data are often difficult to obtain at large spatial scales, which reduces the precision of regional yield estimates. Despite these limitations, our quantitative comparison between observed and simulated yields and further analyses on the factors affecting yield trends have shown some important shift in the past yield records in China.

During the period between 1961 and 2003, dramatic increases in $\mathrm{N}$ input have made the largest contribution to the threefold increase in rice yield, but the effect has been saturated since the early 1980s (Fig. 1, 3; Table 2). Most of the continued increase in grain yield since 1980 is derived from factors other than climate and $\mathrm{N}$ input (represented by $\alpha$ ), in which growth has also slowed in the twenty-first century (Fig. 3). Because the increased amounts of $\mathrm{N}$ application far exceed the crop needs, additional yield increase would not be expected by further increase in $\mathrm{N}$ input. As a penalty of heavy $\mathrm{N}$ fertilization, nitrogen use efficiency represented by PFP for $\mathrm{N}$ has declined dramatically to $30-40 \mathrm{~kg} \mathrm{~kg}^{-1}$ (Fig. 3b). Therefore, improvements in $\alpha$ will continue to play a pivotal role in the future.

An important driver among technological factors is cultivar improvement, which is suggested to be the major contributor to the yield increase since 1980 (Yu et al. 2012). Improvements in yield potential are the primary target of breeding, but efficient use of resources such as $\mathrm{N}$ and water is another important target. Efforts are ongoing, taking advantage of recent advances in molecular genetics (Zhang 2007). How these developments will impact field or regional-level productivity is of paramount importance. Quantitative analyses of the effects of these technological factors will be crucial in this regard.

The future course of cultivar development is also of strong relevance to the impacts of climate change. Tolerance to abiotic stresses such as heat or drought, which are predicted to occur more frequently in the future, is an important target for breeding. Another important aspect of breeding is to enhance productivity by utilizing an unexploited climate resource, namely elevated $\left[\mathrm{CO}_{2}\right]$. This 
aspect has been overlooked, but recent experimental studies have shown substantial genotypic variation in the $\mathrm{CO}_{2}$ fertilization effect (Hasegawa et al. 2013). Traits that perform better under the future climate could be a valuable breeding resource for improvement of resource use efficiency.

The impact of climate changes was much smaller compared with the effect of $\mathrm{N}$ input and technological factors in the past (Table 2), despite significant changes in climatic variables (Table 1). The yield change associated with the climate change was somewhat similar to those reported in recent model analyses (Xiong et al. 2012; Yu et al. 2012). Here, we showed that effects of $\left[\mathrm{CO}_{2}\right]$ differed among provinces, which could be related to temperature and/or $\mathrm{N}$ levels as discussed earlier. Because the effects of projected climate change are expected to be more pronounced in the future (IPCC 2014), understanding the interaction between climate and crop management will become increasingly important. Models including these advances are needed to adequately evaluate climate, cultivar, and management interactions in the future.

Acknowledgments This work was supported by the Global Environment Research Fund of the Ministry of the Environment, Japan (S5-1). We are grateful to Dr. Takeshi Tokida (National Institution for Agro-Environmental Sciences) for fruitful discussions.

Competing interests The authors declare no potential competing interests.

\section{References}

Adachi F (1997) Estimation of evapotranspiration in rice (Oryza sativa L.) under warming climate in Shimane Prefecture. Rep Chugoku Br Crop Sci Soc Jpn 38:1-6

Alexandratos N, Bruinsma J (2012) World agriculture towards 2030/2050: the 2012 revision. Agricultural Development Economics Division, Food and Agriculture Organization of the United Nations, Rome, Italy, pp. 1-147. www.fao.org/economic/esa

Cassman KG, Dobermann A, Walters DT (2002) Agroecosystems, nitrogen-use efficiency, and nitrogen management. AMBIO 31(2):132-140. doi:10.1579/0044-7447-31.2.132

Cassman KG, Dobermann A, Walters DT, Yang H (2003) Meeting cereal demand while protecting natural resources and improving environmental quality. Annu Rev Environ Res 28:315-358. doi:10.1146/annurev.energy.28.040202.122858

Cheng S, Cao L, Yang S, Zhai H (2004) Forty years' development of hybrid rice: China's experience developmental history of hybrid rice experience of hybrid rice Breeding. Rice Sci 11:225-230

Cui J, Kusutani A, Toyota M, Asanuma K (2000) Studies on the varietal difference of harvest index in rice: relationship between harvest index and dry matter production. Jpn J Crop Sci 69:351-358

Evans LT (1993) Crop evolution adaptation and yield. Cambridge University Press, New York, pp 1-500

FAO (2013) FAO statistical yearbook world food and agriculture. Food and Agriculture Organization of the United Nations, Rome, pp 1-289
Farquhar GD, von Caemmerer S, Berry JA (1980) A biochemical model of photosynthesis $\mathrm{CO}_{2}$ assimilation in leaves of $\mathrm{C}_{3}$ species. Planta 149:78-90

Frolking S, Qiu J, Boles S, Xiao X, Liu J, Zhuang Y, Li C, Qin X (2002) Combining remote sensing and ground census data to develop new maps of the distribution of rice agriculture in China. Glob Biogeochem Cycles 16(4):38-1-38-10. doi:10.1029/ 2001GB001425

Gastal F, Lemaire G (2002) N uptake and distribution in crops: an agronomical and ecophysiological perspective. J Exp Bot 53:789-799. doi:10.1093/jexbot/53.370.789

Global Rice Science Partnership (GRiSP) (2013) Rice Almanac, 4th edn. International Rice Research Institute, Los Banos 283

Greenwood DJ, Gastal F, Lemaire G, Draycott A, Millard P, Neeteson JJ (1991) Growth rate and \% N of field grown crops: theory and experiments. Ann Bot 67:181-190

Gregory PJ (2004) Agronomic approaches to increasing water use efficiency. In: Bacon MA (ed) Water use efficiency in plant biology. Blackwell Publishing Ltd, Oxford, pp 142-170

Hasegawa T, Horie T (1997) Modelling the effect of nitrogen on rice growth and development. In: Kropff MJ, Teng PS, Aggarwal PK et al (eds) Applications of systems approaches at the field level, vol 2., Kluwer Academic PublishersLondon, UK, pp 243-257

Hasegawa T, Miyachi Y, Shigaki H, Takano J, Miura M, Sakihara K, Katano M (1995) Prediction of rice growth and yield based on the weather-crop relation in Kumamoto Prefecture I. Prediction of developmental stages. Proc Fac Agric, Kyushu Tokai Univ 14:9-15

Hasegawa T, Shimono H, Iwama K, Nakaseko K (1999) Effects of low water temperature on growth and nitrogen uptake in paddy rice. In. In: Horie T, Geng S, Amano T et al (eds) World food security and crop production technologies for tomorrow. The Crop Science Society of Japan, Kyoto, pp 199-202

Hasegawa T, Sawano S, Goto S, Konghakote P, Polthanee A, Ishigooka Y, Kuwagata T, Toritani H, Furuya J (2008) A model driven by crop water use and nitrogen supply for simulating changes in the regional yield of rain-fed lowland rice in Northeast Thailand. Paddy Water Environ 6:73-82. doi:10. 1007/s10333-007-0099-1

Hasegawa T, Sakai H, Tokida T, Nakamura H, Zhu C, Usui Y, Yoshimoto M, Fukuoka M, Wakatsuki H, Katayanagi N, Matsunami T, Kaneta Y, Sato T, Takakai F, Sameshima R, Okada M, Mae T, Makino A (2013) Rice cultivar responses to elevated $\mathrm{CO}_{2}$ at two free-air $\mathrm{CO}_{2}$ enrichment (FACE) sites in Japan. Funct Plant Biol 40:148-159. doi:10.1071/FP12357

He C-E, Wang X, Liu X, Fangmeier A, Christie P, Zhang F (2010) Nitrogen deposition and its contribution to nutrient inputs to intensively managed agricultural ecosystems. Ecol Appl 20:80-90. doi:10.1890/08-0582.1

Horie T (1994) Crop ontogeny and development. In: Boote KJ, Bennet JM, Sinclair TR, Paulsen GM (eds) Physiology and determination of crop yield. American Society of Agronomy, INC., Crop Science Society of America, INC, Soil Science Society of America, INC., Madison, pp 153-180

Horie T, Nakagawa H, Centeno HGS, Kropff MJ (1995) The rice crop simulation model SIMRIW and its testing. In: Matthews RB, Kropff MJ, Bachelet D, van Laar HH (eds) Modeling the impact of climate change on rice production in Asia. CAB International in association with International Rice Research Institute, Wallingford, pp 51-56

Horie T, Shiraiwa T, Homma K, Katsura K, Maeda S, Yoshida H (2005) Can yields of lowland rice resume the increases that they showed in the 1980s? Plant Prod Sci 8:259-274. doi:10.1626/ pps.8.259

IPCC (2014) Climate Change 2014: impacts, adaptation, and vulnerability. Part A: global and sectoral aspects. Contribution 
of working group II to the fifth assessment report of the intergovernmental panel on climate change. Cambridge University Press, Cambridge

Ishigooka $\mathrm{Y}$, Kuwagata $\mathrm{T}$, Goto $\mathrm{S}$, Toritani $\mathrm{H}$, Ohno $\mathrm{H}$, Urano $\mathrm{S}$ (2008) Modeling of continental-scale crop water requirement and available water resources. Paddy Water Environ 6:55-71. doi:10.1007/s10333-007-0098-2

Katayanagi N, Ono K, Fumoto T, Mano M, Miyata A, Hayashi K (2013) Validation of the DNDC-Rice model to discover problems in evaluating the nitrogen balance at a paddy-field scale for single-cropping of rice. Nutr Cycl Agroecosyst 95:255-268. doi:10.1007/s10705-013-9561-1

Kim H-Y, Lieffering M, Kobayashi K, Okada M, Miura S (2003) Seasonal changes in the effects of elevated $\mathrm{CO} 2$ on rice at three levels of nitrogen supply: a free air $\mathrm{CO}_{2}$ enrichment (FACE) experiment. Glob Chang Biol 9:826-837. doi:10.1046/j.13652486.2003.00641.x

Kimball B, Kobayashi K, Bindi M (2002) Responses of agricultural crops to free-air $\mathrm{CO}_{2}$ enrichment. Adv Agron 77:293-368

Kyaw KM, Toyota K, Okazaki M, Motobayashi T, Tanaka H (2005) Nitrogen balance in a paddy field planted with whole crop rice (Oryza sativa cv. Kusahonami) during two rice-growing seasons. Biol Fertil Soils 42:72-82. doi:10.1007/s00374-005-0856-5

Lemaire G, Oosterom EV, Sheehy J, Jeuffroy MHH, Massignam A, Rossato L (2007) Is crop N demand more closely related to dry matter accumulation or leaf area expansion during vegetative growth? Field Crops Res 100:91-106. doi:10.1016/j.fcr.2006.05. 009

Li T, Hasegawa T, Yin X, Zhu Y, Boote K, Adam M, Bregaglio S, Buis S, Confalonieri R, Fumoto T, Gaydon D, Marcaida M, Nakagawa H, Oriol P, Ruane AC, Ruget F, Singh B, Singh U, Tang L, Tao F, Wilkens P, Yoshida H, Zhang Z, Bouman B (2014) Uncertainties in predicting rice yield by current crop models under a wide range of climatic conditions. Glob Chang Biol, doi: 10.1111/gcb.12758

Liu X, Duan L, Mo J, Du E, Shen J, Lu X, Zhang Y, Zhou X, He C, Zhang F (2011) Nitrogen deposition and its ecological impact in China: an overview. Environ Pollut 159:2251-2264. doi:10. 1016/j.envpol.2010.08.002

Lobell DB, Schlenker W, Costa-Roberts J (2011) Climate trends and global crop production since 1980. Science 333:616-620. doi:10. 1126/science. 1204531

Long SP (1991) Modification of the response of photosynthetic productivity to rising temperature by atmospheric $\mathrm{CO}_{2}$ concentrations: has its importance been underestimated? Plant Cell Environ 14:729-739. doi:10.1111/j.1365-3040.1991.tb01439.x

Makino A, Shimada T, Takumi S, Kaneko K, Matsuoka M, Shimamoto K, Nakano H, Miyao-Tokutomi M, Mae T, Yamamoto N (1997) Does decrease in ribulose-1,5-bisphosphate carboxylase by antisense $\mathrm{RbcS}$ lead to a higher $\mathrm{N}$-use efficiency of photosynthesis under conditions of saturating $\mathrm{CO}_{2}$ and light in rice plants? Plant Physiol 114:483-491

Nakagawa H, Horie T (1995) Modelling and prediction of developmental process in rice : II. A model for simulating panicle development based on daily photoperiod and temperature. Jpn J Crop Sci 65:33-42

Peng S, Garcia FV, Gines HC, Laza RC, Samson MI, Sanico AL, Visperas RM, Cassman KG (1995) Nitrogen use efficiency of irrigated tropical rice established by broadcast wet-seeding and transplanting. Fertil Res 45:123-134. doi:10.1007/BF00790662

Peng S, Laza RC, Visperas RM, Sanico AL, Cassman KG, Khush GS (2000) Grain yield of rice cultivars and lines developed in the Philippines since 1966. Crop Sci 40:307. doi:10.2135/ cropsci2000.402307x

Peng S, Tang Q, Zou Y (2009) Current status and challenges of rice production in China. Plant Prod Sci 12:3-8. doi:10.1626/pps.12.3
Ritchie JT, NeSmith DS (1991) Temperature and crop development. In: Hanks J, Ritchie JT (ed) Modeling plant nad soil systems, Agronomy M. American Society of Agronomy, INC., Crop Science Society of America, INC, Soil Science Society of America, INC., Madison, pp 5-29

Sakai H, Hasegawa T, Kobayashi K (2006) Enhancement of rice canopy carbon gain by elevated $\mathrm{CO}_{2}$ is sensitive to growth stage and leaf nitrogen concentration. New Phytol 170:321-332. doi:10.1111/j.1469-8137.2006.01688.x

Sawano S, Hasegawa T, Goto S, Konghakote P, Polthanee A, Ishigooka Y, Kuwagata T, Toritani H (2008) Modeling the dependence of the crop calendar for rain-fed rice on precipitation in Northeast Thailand. Paddy Water Environ 6:83-90. doi:10. 1007/s10333-007-0102-x

Seligman NG, van Keulen H, Goudriaan J (1975) An elementary model of nitrogen uptake and redistribution by annual plant species. Oecologia 21:243-261. doi:10.1007/PL00020264

Shimono H, Hasegawa T, Iwama K (2007) Modeling the effects of water temperature on rice growth and yield under a cool climate. I. Model development. Agron J 99:1327-1337. doi:10.2134/ agronj2006.0337

Shindo J (2013) Nitrogen flow model as a tool for evaluation of environmental performance of agriculture and effects on water environment. J Dev Sustain Agric 12:1-12

Shindo J, Okamoto K, Kawashima H (2006) Prediction of the environmental effects of excess nitrogen caused by increasing food demand with rapid economic growth in eastern Asian countries, 1961-2020. Ecol Model 193:703-720. doi:10.1016/j. ecolmodel.2005.09.010

Sinclair TR, Tanner CB, Bennett JM (1984) Water-use efficiency in crop production. Bio Sci 34(1):36-40. doi:10.2307/1309424

Song XF, Agata W, Kawamitsu Y (1990) Studies on dry matter and grain production of F1 Hybrid rice in China : I. Characteristics of dry matter production. Jpn J Crop Sci 59:19-28. doi:10.1626/jcs. 59.19

Steduto P, Hsiao TC, Raes D, Fereres E (2009) AquaCrop-The FAO crop model to simulate yield response to water: I. Concepts and underlying principles. Agron J 101:426-437

Stehfest E, Heistermann M, Priess JA, Ojima DS, Alcamo J (2007) Simulation of global crop production with the ecosystem model DayCent. Ecol Model 209:203-219. doi:10.1016/j.ecolmodel. 2007.06.028

Sugihara S, Konno T, Ishii K (1986) Kinetics of mineralization of organic nitrogen in soil. Bull Natl Inst Agro-Environ Sci 1:127-166

Tao F, Yokozawa M, Xu Y, Hayashi Y, Zhang Z (2006) Climate changes and trends in phenology and yields of field crops in China, 1981-2000. Agric For Meteorol 138:82-92. doi:10.1016/ j.agrformet.2006.03.014

Tao F, Yokozawa M, Liu J, Zhang Z (2008) Climate-crop yield relationships at provincial scales in China and the impacts of recent climate trends. Clim Res 38:83-94. doi:10.3354/cr00771

Toriyama K (2002) Estimation of fertilizer nitrogen requirement for average rice yield in Japanese paddy fields. Soil Sci Plant Nutr 48:293-300. doi:10.1080/00380768.2002.10409204

Xiao D, Tao F (2014) Contributions of cultivars, management and climate change to winter wheat yield in the North China Plain in the past three decades. Eur J Agron 52:112-122. doi:10.1016/j. eja.2013.09.020

Xiong W, Holman I, Lin E, Conway D, Li Y, Wu W (2012) Untangling relative contributions of recent climate and $\mathrm{CO}_{2}$ trends to national cereal production in China. Environ Res Lett 7:44014

Xu J, Masuda K, Ishigooka Y, Kuwagata T, Haginoya S, Hayasaka T, Yasunari T (2011) Estimation and verification of daily surface shortwave flux over China. J Meteorol Soc Jpn Ser II 89A:225-238. doi:10.2151/jmsj.2011-A14 
Yan X, Cai Z, Ohara T, Akimoto H (2003) Methane emission from rice fields in mainland China: amount and seasonal and spatial distribution. J Geophys Res Atmospheres 108(D16):4505. doi:10.1029/2002JD003182

Yin X (2013) Improving ecophysiological simulation models to predict the impact of elevated atmospheric $\mathrm{CO}_{2}$ concentration on crop productivity. Ann Bot 112:465-475. doi:10.1093/aob/ met016

Yin X, Kropff MJ, Horie T, Nakagawa H, Centeno HGS, Zhu D, Goudriaan J (1997) A model for photothermal responses of flowering in rice I. Model description and parameterization. Field Crops Res 51:189-200. doi:10.1016/S0378-4290(96)03456-9

Yin X, Lantinga EA, Schpendonk ADHCM, Zhong X (2003) Some quantitative relationships between leaf area index and canopy nitrogen content and distribution. Ann Bot 91:893-903. doi:10. 1093/aob/mcg096

Yoneyama S, Sano C (1978) Nitrogen nutrition and growth of the rice plant II. Considerations concerning the dynamics of nitrogen in rice seedlings. Soil Sci Plant Nutr 24:191-198

Yoshimoto M, Oue H, Kobayashi K (2005) Energy balance and water use efficiency of rice canopies under free-air $\mathrm{CO}_{2}$ enrichment. Agric For Meteorol 133:226-246. doi:10.1016/j.agrformet.2005. 09.010
Yu Y, Huang Y, Zhang W (2012) Changes in rice yields in China since 1980 associated with cultivar improvement, climate and crop management. Field Crops Res 136:65-75. doi:10.1016/j.fcr. 2012.07.021

Zhang Q (2007) Strategies for developing green super rice. Proc Natl Acad Sci USA 104:16402-16409. doi:10.1073/pnas.0708013104

Zhang S, Tao F (2013) Modeling the response of rice phenology to climate change and variability in different climatic zones: comparisons of five models. Eur J Agron 45:165-176. doi:10. 1016/j.eja.2012.10.005

Zhang T, Zhu J, Wassmann R (2010) Responses of rice yields to recent climate change in China: an empirical assessment based on longterm observations at different spatial scales (1981-2005). Agric For Meteorol 150:1128-1137. doi:10.1016/j.agrformet.2010.04.013

Zhou Y, Li N, Dong G, Wu W (2013) Impact assessment of recent climate change on rice yields in the Heilongjiang Reclamation Area of north-east China. J Sci Food Agric 93:2698-2706. doi:10.1002/jsfa.6087

Zou J, Huang Y, Qin Y, Liu S, Shen Q, Pan G, Lu Y, Liu Q (2009) Changes in fertilizer-induced direct $\mathrm{N} 2 \mathrm{O}$ emissions from paddy fields during rice-growing season in China between 1950s and 1990s. Glob Chang Biol 15:229-242. doi:10.1111/j.1365-2486. 2008.01775.x 